\title{
Formação de professores de educação física e usos de conceitos do campo comunicacional para pensar o ensino
}

Allyson Carvalho de Araújo Professor adjunto da Universidade Federal do Rio Grande do Norte (UFRN). Professor permanente do Programa Pós-Graduação em Educação Física (PPGEF/UFRN).

Doutor em Comunicação pela Universidade Federal do Pernambuco (UFPE).

E-mail: allyssoncarvalho@hotmail.com

Marcio Romeu Ribas de Oliveira Professor adjunto da Universidade Federal do Rio Grande do Norte (UFRN). Professor permanente do Programa Pós-Graduação em Educação Física (PPGEF/UFRN). Doutor em Educação pela Universidade do Estado do Rio de Janeiro (UFRJ).

E-mail: marcioromeu72@gmail.com

Antonio Fernandes de Souza Júnior Professor substituto da Universidade Federal do Rio Grande do Norte (UFRN). Professor da rede pública municipal de Ceará-Mirim (RN). Mestre em Educação Física pela Universidade Federal do Rio Grande do Norte (UFRN).

E-mail: antonio.fernandes.jr@hotmail.com

Resumo: A dinâmica social contemporânea, marcada por aceleradas trocas simbólicas em suportes com multilinguagens, tem requerido urgentemente novos processos de ensino-aprendizagem. A partir deste relato de experiência, objetivamos refletir sobre o processo de formação continuada de professores de educação física na cidade de Natal (RN) ao acionar conceitos oriundos do campo comunicacional, mas que implicam novas formas de ensinar. A descrição é tributária de uma pesquisa-ação e tem por base a observação sistemática de encontros de formação continuada realizados em 2016. Ao resgatar os
Abstract: Contemporary social dynamics, marked by accelerated symbolic exchanges with the support of multi-language, have urgently required new teachinglearning processes. The objective of this experience report is to reflect on the process of continuing education to physical education teachers in the city of Natal, RN, using communication concepts that imply new teaching methods. The description is the result of action research and is based on systematic observation of continuing education meetings held in 2016. By using narrative and 
conceitos de narrativa e comunicação, além do processo de mediação, compreendemos que os professores demonstram reconhecer e refletir sobre tais conceitos na medida em que estes são problematizados em suas práticas pedagógicas, sendo possível experimentá-los no cotidiano escolar.

Palavras-chave: mediação; narrativa; comunicação; formação continuada; educação física. communication concepts and a mediation process, teachers recognize and reflect on such concepts as they are discussed in their pedagogical practices, allowing them to experience these concepts in daily school routine.

Keywords: mediation; narrative; communication; continuing education; physical education.

\section{INTRODUÇÃO}

Reconhecendo que os discursos midiáticos perpassam as práticas culturais na sociedade contemporânea, alterando suas dinâmicas comunicacionais, entendemos que os estudos sobre a mídia constituem um eixo interdisciplinar necessário a toda e qualquer formação acadêmica. No campo educacional, crescem em quantidade e aprofundamento teórico-metodológico as iniciativas que visam compreender e implementar as interações possíveis e necessárias da educação formal com os meios de comunicação. Admite-se que a mídia produz e veicula sentidos/significados próprios para a cultura escolar, além de difundir um tipo de conteúdo cuja assimilação se dá por meio das novas linguagens e da convergência das tecnologias. Assim, é necessária uma formação de professores que oportunize o acesso sistematizado aos conceitos e às linguagens midiáticas a fim de que possam se apropriar de ferramentas conceituais e técnicas para compreender e ressignificar as literacias emergentes ${ }^{1}$, buscando associá-las aos temas da cultura escolar.

Considerando que a formação inicial não consegue responder a todas as

1. PASSARELLI, Brasilina; JUNQUEIRA, Antonio Helio; ANGELUCl, Alan César Belo. Digital natives in Brazil and their behavior in front of the screens. MATRIZes, São Paulo, v. 8, n. 1, p. 159-178, 2014

2. MELO, José Pereira; BORBA, Sandra (org.). Caderno informativo do Paideia: a importância do ensino de Arte e Educação Física na escola. Natal: Paideia, 2006, p. 12

3. PIRES, Giovani De Lorenzi et al. A pesquisa em Educação Física e mídia: pioneirismo, contribuições e críticas ao "Grupo de Santa Maria". Movimento, Porto Alegre v. 14, n. 3, p. 33-52, 2008. demandas requeridas do ofício docente, a literatura atual tem apostado na formação continuada como "processo interativo e dinâmico, individual e coletivo, que ocorre atrelado aos projetos da escola, constituindo-se numa rede de produção de saberes e de desenvolvimento da organização curricular"² que deve buscar relacionar-se com as mudanças culturais mais amplas para oxigenar a prática pedagógica, tal como a emergência das mediações oportunizada pelos suportes comunicacionais.

Já existe a percepção de um movimento de aproximação gradativo e concêntrico entre o campo pedagógico e o da comunicação - que convergem na educação física, de forma mais sistemática, a partir da década de $1990^{3}$ - e que vem se fortalecendo ao longo dos anos. Essa aproximação tem gerado inquietações e significativas experiências no espaço escolar ao problematizar e oportunizar aos jovens e crianças expressões relacionadas aos aspectos da veiculação, do consumo, da apropriação e da análise crítica dos discursos midiáticos, a partir dos temas pedagógicos da educação física. 
Várias são as definições atribuídas a essa perspectiva educacional. Contudo, atualmente temos como termos mais utilizados no Brasil os conceitos de "educomunicação" e de "mídia-educação" ${ }_{5,6}$ que, embora tragam em suas contextualizações algumas divergências, foram responsáveis por alicerçar um novo pensar acerca dos processos comunicacionais em espaços educativos, sendo, desta forma, um aporte teórico responsável por possibilitar uma perspectiva qualitativa e inovadora da prática pedagógica.

Porto $^{7}$ preconiza que é necessário o desenvolvimento de uma pedagogia da comunicação que, além de utilizar os dispositivos tecnológicos como ferramentas ou recursos facilitadores da aprendizagem, proporcione um contato reflexivo e crítico com a cultura da mídia, analisando suas mensagens e compreendendo como os seus sentidos são tecnicamente construídos pelos recursos tecnológicos.

Neste sentido, é interessante tematizar, problematizar e produzir espaços de formação (inicial e continuada) de professores para que estes percebam nesse campo outras possibilidades de ensino e explorem no tempo-espaço escolar uma maior variedade de temas e saberes que habitam a cultura midiática. Nesse intento, gostaríamos de pautar especificamente neste relato o contexto da formação continuada de professores de educação física escolar.

A nossa reflexão, portanto, emerge de um processo formativo que se desenvolveu em encontros quinzenais com os professores de educação física da rede municipal de ensino da cidade de Natal ( $\mathrm{RN})$, efetivado em parceria entre a Universidade Federal do Rio Grande do Norte (UFRN), por meio do Laboratório de Estudos em Educação Física, Esporte e Mídia (Lefem), e a Secretaria Municipal de Educação (SME) de Natal, que resultou no Programa de Formação Continuada de Professores de Educação Física (Foco-EF).

Esse programa tem como escopo tematizar e difundir o tema da mídia-educação entre os professores de educação física em atuação na cidade de Natal. A ação de formação continuada foi operacionalizada por um programa de extensão, vinculado à UFRN e coordenado pelo Lefem, denominado "Formação de professores(as) de Educação Física: dialogando os saberes disciplinares, escola e cultura midiática em tempos de megaeventos esportivos", que foi financiado pelo edital de 2016 do Programa de Apoio à Extensão Universitária (ProExt) do Ministério da Educação (MEG).

É interessante notar que, ao buscar sistematizar informações sobre a mídia-educação e a formação continuada em educação física, encontramos outras experiências já relatadas por Mendes $^{8}$ e por Bianchi ${ }^{9}$ que nos inspiraram a respeito das possibilidades de articulação temática para a proposta desse trabalho. No texto que se apresenta daremos ênfase às questões que emergiram dos encontros de formação, enquanto problemáticas do campo, tendo como fundamentação os conceitos do campo comunicacional. Neste sentido, objetivamos refletir sobre o processo de formação continuada de professores de educação física na cidade de Natal ao acionar conceitos que migram do campo comunicacional, mas implicam novas formas de ensinar.
4. SOARES, Ismar de Oliveira. Educomunicação: o conceito, o profissional, a aplicação: contribuições para a reforma do Ensino Médio. São Paulo: Paulinas, 2011.

5. FATIN, Monica. Mídia-educação: conceitos, experiências, diálogos Brasil-Itália. Florianópolis: Cidade Futura, 2006.

6. BELLONI, Maria Luiza. O que é mídia-educação? Campinas: Autores Associados, 2001.

7. PORTO, Tania Maria Esperon. As tecnologias de comunicação e informação na escola: relações possíveis... relações construídas. Revista Brasileira de Educação, Rio de Janeiro, v. 11, n. 31, p. 43-57, 2006.

8. MENDES, Diego de Sousa. Luz, câmera e pesquisa-ação: uma inserção na mídia-educação na educação continuada de professores de educação física. 2008. Dissertação (Mestrado em Educação Física) - Universidade Federal de Santa Catarina, Florianópolis, 2008.

9. BIANCHI, Paula. Formação em mídia-educação (física): ações colaborativas na rede municipal de Florianópolis/Santa Catarina. 2009. Dissertação (Mestrado em Educação Física) - Universidade Federal de Santa Catarina, Florianópolis, 2009. 
comunicação \& educação • Ano XXIV • número 1 • jan/jun 2019

10. BARBIER, René. A pesquisa-ação. Brasília, DF: Líber Livro, 2007.

11. SOUZA JÚNIOR, Antonio Fernandes de. Os docentes de educação física na apropriação da cultura digital: encontros com a formação continuada. Dissertação. 2018. Dissertação (Mestrado em Educação Física) - Centro de Ciências da Saúde, Universidade Federal do Rio Grande do Norte, Natal, 2018, p. 84

12. Os encontros de formação foram realizados no ano de 2016, às segundas-feiras, no Centro Municipal de Referência Escolar (Cemure). Participavam os professores vinculados ao laboratório Lefem, estudantes de mestrado, bolsistas vinculados ao projeto de extensão, formadores da Prefeitura Municipal de Natal e professores da rede pública municipal. Os encontros eram filmados e fotografados, e depois eram realizadas avaliações pelos professores, mestrandos e bolsistas do projeto, as quais compreendiam nossas observações sobre a formação. Nesses processos avaliativos, debatíamos sobre nossas impressões a respeito dos encontros e organizávamos os próximos, num processo de avaliação-ação-reflexão-ação.

13. GIL, Antonio Carlos. Como elaborar projetos de pesquisa. São Paulo: Atlas, 2010.

14. Com a intenção de garantir o anonimato dos docentes, utilizamos as iniciais de seus nomes para identificar seus depoimentos.

\section{NOSSO PERCURSO E FORMA DE NARRAR}

$\mathrm{O}$ relato é fruto de um estudo descritivo de abordagem qualitativa. O instrumento de coleta de dados foi a observação participante dos encontros de formação continuada em 2016 no município de Natal. A pesquisa que originou o relato respalda-se em uma postura metodológica de intervenção social, fundamentada no método de pesquisa-ação ${ }^{10}$, uma vez que o objetivo desse método, assim como o nosso, é promover mudanças em uma realidade social (tendo como hipótese que a realidade necessita de mudanças).

O universo em que se insere nossa experiência é constituído por 155 docentes de educação física em atuação nas 73 escolas públicas espalhadas pelo município de Natal. Contudo, a amostra que representa o que foi vivenciado caracteriza-se por um grupo de 96 professores, correspondendo a um total de, aproximadamente, dois terços do número de docentes de educação física do município que aderiram à formação continuada.

Em breve caracterização dos professores, recorremos aos dados apontados por Souza Júnior ${ }^{11}$ para esclarecer que esses docentes tinham média de idade de 41 anos, formação inicial em educação física na UFRN ou na Universidade do Estado do Rio Grande do Norte (UERN), na primeira década deste século, e não atestavam ter vivenciado algum diálogo com os estudos da mídia ou do campo da comunicação nessas formações. A maior parte dos professores participantes do programa são pós-graduados (latu sensu) e acessam a internet principalmente para interagir em redes sociais. A expressiva maioria aponta a televisão como equipamento de acesso mais recorrente às mídias, de maior intimidade e de maior acionamento em práticas pedagógicas. Por outro lado, o videogame é o dispositivo de menor recorrência de uso e disponibilidade no espaço escolar.

No que se refere às técnicas e aos instrumentos de coleta de dados, utilizaremos como base de nosso relato a observação-participante ${ }^{12}$ e o diário de campo $^{13}$. Acessoriamente são utilizadas ainda algumas fotografias como forma de ilustrar a experiência vivida. Todas as inferências postas nesse relato partem de reflexões do grupo de formadores.

\section{CONCEITOS DO CAMPO COMUNICACIONAL DISCUTIDOS NA FORMAÇÃO}

O primeiro encontro conduzido pelo Lefem estabeleceu a seguinte questão como guia dessa interlocução: como as mídias e as tecnologias atravessam as escolas, as aulas e os nossos alunos e alunas? A proposta era fazer uma rede de saberes e opiniões sobre as formas de acesso às mídias e tecnologias no espaço escolar e sobre a postura dos professores quanto a elas. Percebemos uma multiplicidade de posturas, depoimentos e discursos, dos quais destacamos alguns, colhidos no encontro de 25 de abril de $2016^{14}$ : 
O WhatsApp tem sido uma ferramenta fantástica para essa comunicação sobre esportes com os meninos, sobre as competições, com informações de horários [...]. Porém o que vejo só fica ai, nas redes sociais e das selfies com adolescentes [...]. (GGB, 2016)

era indiferente, pois, como eu trabalho com os alunos menores lá na escola, eles não levam celular. Na escola, no momento, eles não têm acesso a nenhuma mídia. Pode ser que tenham em casa. Quando vêm de casa, eles não trazem nenhuma informação. [...] eu perder esse momento de educação motora por outro, sinceramente... É um elemento para você usar, um recurso, mas não pode ser o modo principal da educação física. (HGACS, 2016)

No desenvolvimento dos debates nesse e em outros encontros da formação de professores de educação física, algumas resistências emergiram e expressavam certas inconsistências de compreensão do processo comunicacional no espaço educativo. Tais inconsistências nos levaram a refletir sobre a necessidade de pensar o processo comunicativo de forma mais ampla e ao mesmo tempo aplicada à educação. A justificativa de pensar o processo comunicativo, mas nos centrando ainda no campo da educação, se ancora tanto no diálogo com professores quanto na potência demonstrada pelos primeiros movimentos de uma teoria latino-americana da comunicação em diálogo com a educação ${ }^{15}$.

A decisão tomada foi a de operar a partir conceitos que, emprestadas do campo comunicacional, poderiam nos ajudar a pensar sobre o ensino. Tais conceitos emergem de diferentes maneiras no debate durante a formação, como em uma tirinha produzida pelos professores, nas interações entres os atores da pesquisa e os dispositivos tecnológicos, ou mesmo no diálogo sobre a organização das experiências pedagógicas. Esses momentos preciosos e singulares, de pequenos estranhamentos, possibilitaram compreender de forma distinta as formas de aprender e ensinar com as tecnologias, de modo que esses conceitos puderam ser debatidos e vividos na formação.

Neste texto nos centramos em duas cenas vividas com os professores de educação física da rede pública de ensino, a partir das quais discutimos os conceitos de narrativa e comunicação.

\section{RELATANDO CENAS E PENSANDO CONCEITOS}

\subsection{Experiências e reflexões dos professores a respeito do conceito de narrativa}

A primeira cena é um desdobramento da rede de saberes e opiniões sobre mídias e tecnologias na escola. No primeiro momento, ao nos dividirmos em grandes grupos de professores, realizamos uma atividade que consistia em narrar a partir do questionamento do encontro. Assim, simbolicamente, as narrativas foram sendo conectadas por um barbante (Figura 1), ao mesmo tempo em que um mediador problematizava os discursos. Dessa forma, houve o estabelecimento de uma rede de experiências.

15. MARTÍN-BARBERO, Jesús. A comunicação na educação. Tradução de Maria Immacolata Vassallo de Lopes e Dafne Melo. São Paulo: Contexto, 2014. 


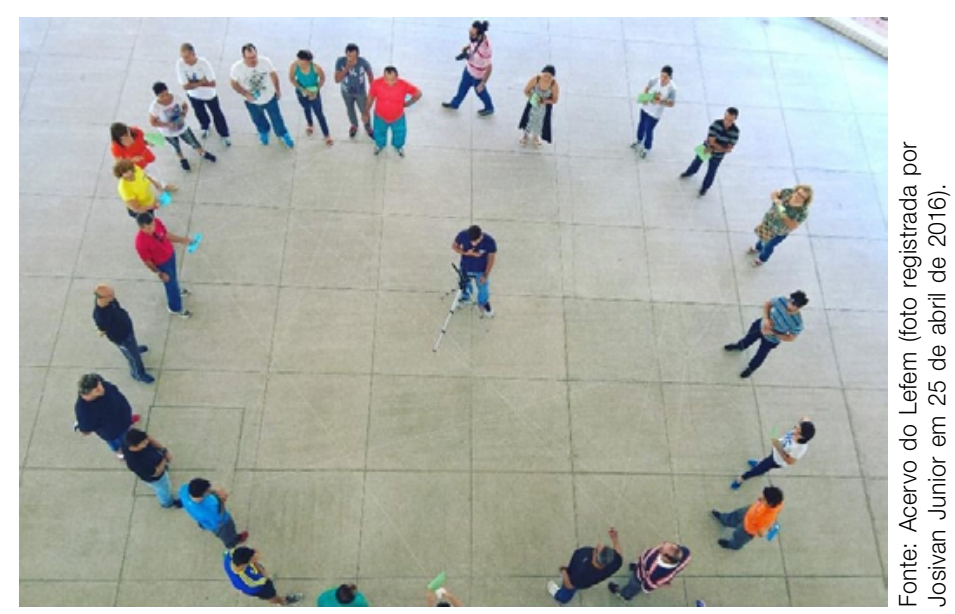

Figura 1: Rede de saberes e opiniões

Percebemos nos discursos desses professores diferentes experiências, que remeteram a distintas compreensões sobre mídia, educação e educação física. Em todos os casos, de alguma forma percebia-se a mídia como fenômeno que tem dialogado com a escola e os sujeitos que nela se inserem, reafirmando, dessa forma, a necessidade de diálogo. A partir desse momento, foi proposto o desafio de produzir, em pequenos coletivos, narrativas sobre o debate posto por meio dos tablets disponibilizados para esse fim (Figura 2).

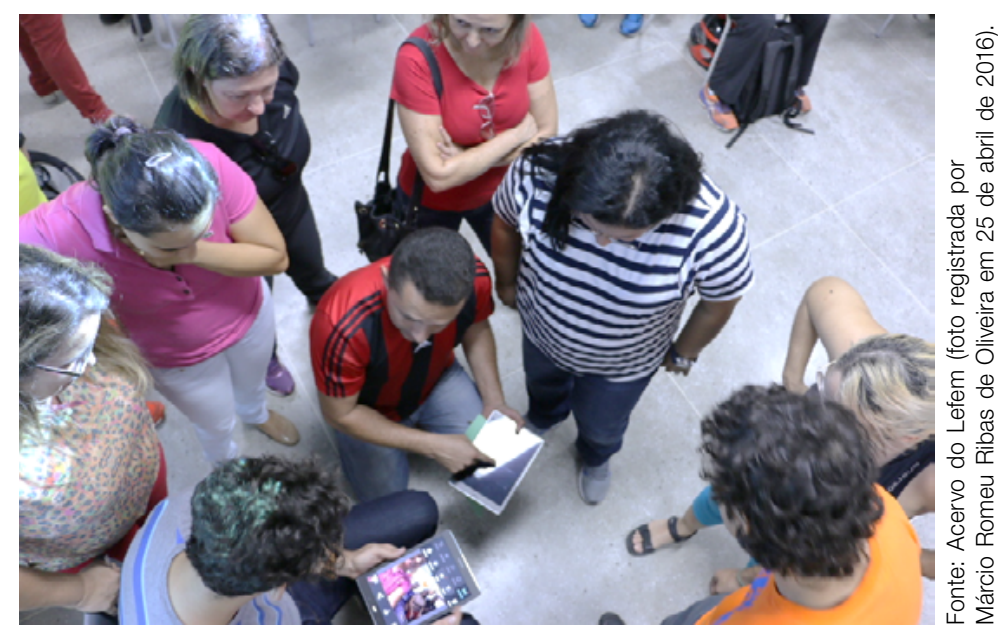

Figura 2: Diálogos sobre as produções

Nesse momento percebemos as diferentes relações estabelecidas com os dispositivos, desde a dificuldade para ligar o aparelho e a não percepção de toda a usabilidade disposta pelo dispositivo, até a falta de habilidade na produção e edição de vídeos (linguagem mais recorrente entre professores nesta atividade).

Ficou evidente que o processo de construção da narrativa teve diferentes formas de elaboração e níveis de criatividade na medida em que o coletivo se relacionava com os dispositivos. Assim, foram produzidas narrativas por meio de fotografias, tirinhas ou entrevistas, encenações teatrais e diálogos gravados. 
Diferentemente das proposições de construção de sínteses orais ou escritas, o desafio com o dispositivo "estranho" colocou em questão a habilidade dos professores de narrar um acontecimento e suas expressões sobre o ocorrido. A situação nos fez lembrar esta afirmação de Walter Benjamin: "torna-se cada vez mais raro o encontro com pessoas que sabem narrar alguma coisa direito" ${ }^{\text {. }}$

Não se referindo aos dispositivos digitais, mas talvez vanguardista ao pensar a partir de um momento histórico de rápidas transformações, esse autor ainda argumenta que "é como se uma faculdade, que nos parecia inalienável, a mais garantida entre as coisas seguras, nos fosse retirada. Ou seja: a de trocar experiências"17.

Benjamin conceitua o sentido do ato narrativo como capacidade ligada ao encontro e à possibilidade de partilhar coisas e nos comunicarmos, exercida ao contar e ao ouvir as mais diversas narrativas. Nesses termos, é possível acreditarmos na prática de narrar como atividade interativa e comunicável. Tal experiência estaria em declínio, segundo o autor, por ser pouco praticada e ter baixa qualidade.

Esses sentidos dos primeiros pensamentos benjaminianos sobre a capacidade de narrar podem nos impulsionar a fazer algumas questões a partir do estranhamento dos professores: nós temos habilidades para tecer nossas narrativas contemporâneas com os dispositivos tecnológicos? Se sim, essa habilidade estaria mais no domínio técnico ou na compreensão das implicações de uma nova linguagem?

Ao pensarmos, junto com Benjamin, que nossas capacidades comunicativas estariam em declínio, é possível considerar que tecnologias e os meios de comunicação de massa estariam influenciando sobremaneira nossas práticas de narração e, portanto, de comunicação.

$\mathrm{O}$ autor indicava a iminência da substituição das narrativas comunicantes, presentes nos modos de ser e viver e que, por conta de outros suportes e experiências na modernidade, estavam sendo modificadas. A afirmação pode ser ilustrada pela caracterização das mudanças decorrentes da modernidade feita por Lévy ${ }^{18}$, para quem a comunicação de massa conheceu seu apogeu em meados do século XIX e alterou nossa experiência no mundo.

Essas novas máquinas e objetos modernos utilizados para transmitir nossas experiências estariam diminuindo a vivência cotidiana do encontro e das conversas, ou poderiam ser um dado precursor de algo em movimento na cultura. Em nossa observação da cena com os professores, o reconhecimento da necessidade de pensar a cultura midiática no contexto educativo é perceptível nos discursos docentes; porém algumas questões são problematizadas, sobretudo as que se dirigem à relação e à apropriação do domínio técnico dos dispositivos digitais pelos professores.

Essas inquietações, aliadas às reflexões realizadas em nossas observações, nos levaram a estabelecer um novo plano de ação para o próximo encontro com os professores. O plano se inclinou a refletir sobre o conceito de "narrativa", focalizando as narrativas sobre o Jogos Olímpicos de 2016. Assim, discutiu-se

16. BENJAMIN, Walter O narrador: considerações sobre a obra de Nikolai Leskov. In: Magia e técnica, arte e política: ensaios sobre literatura e história da cultura. São Paulo: Editora Brasiliense, 1987, p. 57.

17 . Ibidem, p. 57.

18. LÉVY, Pierre. A inteligência coletiva: por uma antropologia do ciberespaço. Lisboa: Instituto Piaget, 1994. 
a educação olímpica e, posteriormente, foram apresentados vídeos divulgados pela organização das Olimpíadas daquele ano.

A proposta para o encontro se concretizou na produção de narrativas sobre os Jogos Olímpicos por meio de um aplicativo ( $a p p$ ) chamado "Comic Strip It!", que possibilita a criação de histórias em quadrinhos a partir de fotografias que, organizadas em sequência e com recursos específicos, criam uma narrativa - não possível apenas por meio de seus elementos e funções tomados de forma isolada (Figura 3). Essas atividades se efetivaram em uma perspectiva técnico-instrumental, de modo que as funcionalidades do $a p p$ foram explicadas ao grupo de professores. Porém percebemos que nossa atividade não estava estabelecendo uma relação de partilha, mas uma ação informativa, como demonstraremos adiante.

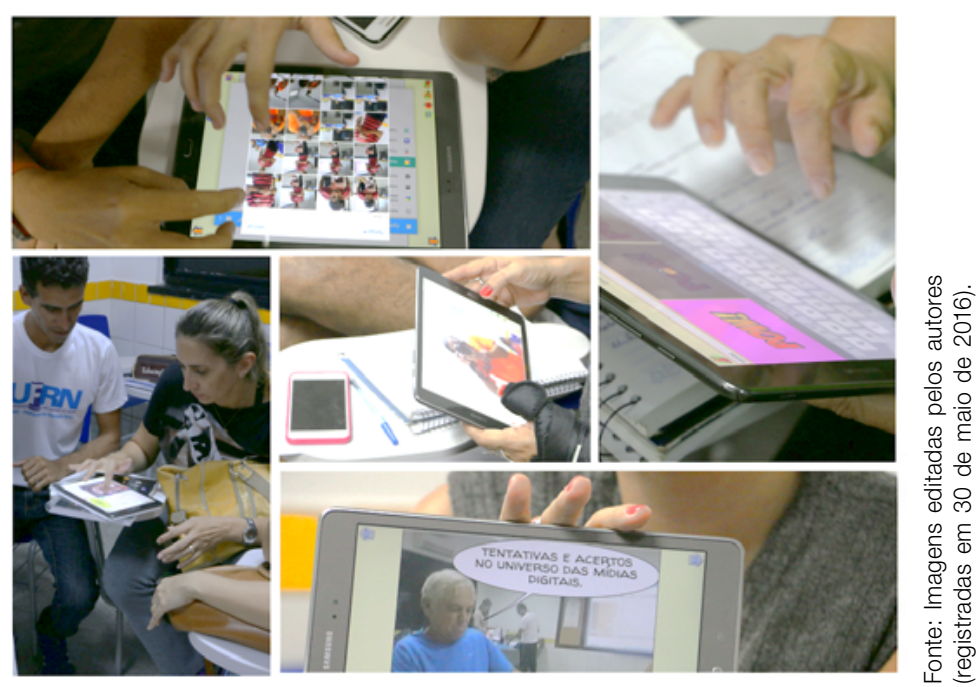

Figura 3: Criando as narrativas digitais (histórias em quadrinhos)

O ponto positivo do momento de formação foi perceber que a experiência de construir uma história em quadrinhos pelo aplicativo, manipulando os tablets, ofertou aos professores a percepção de como as narrativas sobre o corpo e as práticas corporais podem ser manipuladas pelos meios de comunicação de massa. Conforme nossa observação sobre a atividade, foi o movimento de descoberta técnica que acionou uma postura crítica, a ponto de modificar positivamente a atitude do professor com relação ao uso das mídias e da tecnologia em suas práticas pedagógicas.

\subsection{Experiências e reflexões dos professores a respeito do conceito de comunicação}

Apesar de o processo de construção da narrativa ter nos feito refletir sobre as formas como os professores se relacionam com os dispositivos e suas usabilidades, um dos produtos finais da atividade também nos chamou atenção. 
Trata-se de uma tirinha narrativa em que um dos grupos de professores fez uso de uma foto para narrar e ironizar um dos formadores que havia se proposto a explicar a usabilidade do aplicativo.

$\mathrm{Na}$ referida tirinha (Figura 4), a imagem, o texto e o layout apontam a compreensão da linguagem proposta pelo aplicativo, mas a produção de sentido sugerida pelo produto apontava para outra questão cara ao âmbito educacional e fundante para o campo comunicacional: a noção de comunicação.

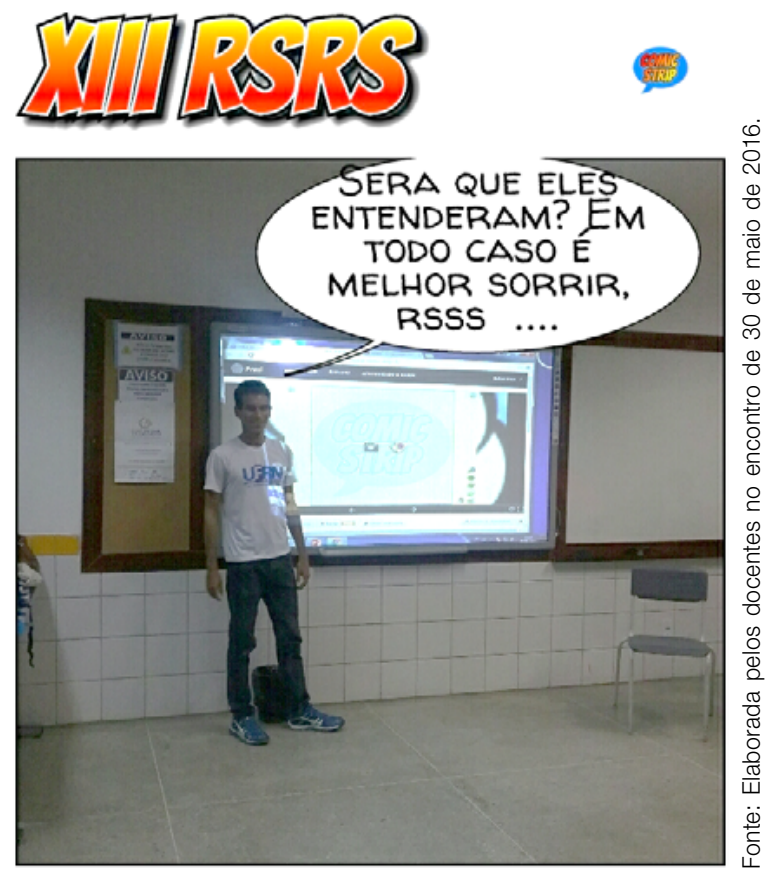

Figura 4: Será que eles entenderam?

Ao receber a "tirinha", o grupo de formadores se indaga: estamos dando comunicados ou estabelecendo uma interação comunicativa? Claramente a autorreflexão se ampara na preocupação sobre a atitude antidialógica que ficou materializada na percepção e na narrativa de um dos grupos. Ora, ao passo que os formadores buscavam uma atitude de construção e de descoberta via experimentação de dispositivos, o momento de ensino expositivo e tradicional ainda foi destacado pelo grupo de professores, talvez ironizando, inclusive, seu sucesso ao explicar as funcionalidades do $a p p$.

A demanda de refletir sobre esses processos de condução da formação nos levou a pensar que as práticas da cultura digital midiática na sociedade contemporânea compreendem elementos informacionais e comunicacionais. Vivemos um momento em que há muitas transmissões ${ }^{19}$ de mensagens, com acesso a vários tipos de informação, nos mais variados suportes e plataformas, e as características dos modos de conhecer e interagir com essas informações integram as tecnologias de transmissão de informações (TTI).

Há uma capacidade no uso e no ensaio das tecnologias e das informações, como argumenta Gutierrez ${ }^{20}$, de "transformar os meios de informação em meios
19. Entendemos a necessidade de problematizar algumas compreensões do sentido de "comunicação" que estão mais próximas do sentido de "transmissão", muito por conta da teoria matemática da comunicação de Weaver (1977). Tal situação indica que as tecnologias são muito mais de transmissão de mensagens e de informação do que efetivamente de comunicação.

20. GUTIÉRREZ, Francisco. Linguagem total: uma pedagogia dos meios de comunicação. São Paulo: Summus, 1978, p. 20. 
21. SOARES, Ismar de Oliveira. Gestão comunicativa e educação: caminhos da educomunicação. Comunicação \& Educação, São Paulo, n. 23, p. $16-25,30,2002$, p. 18.

\section{BENJAMIN, op. cit.}

23. Esse elemento relacionado à comunicação é um conceito que foi debatido nos processos avaliativos da formação. Percebíamos que em vez de propormos processos comunicativos e dialógicos nos encontros da formação, estávamos produzindo comunicados e transmitindo informações. Essa avaliação fez com que percebêssemos que as práticas comunicativas precisam ser compreendidas como espaços coletivos de comunicação, com respeito às diversidades e ampliando nossas oportunidades de compartilhar e dialogar coletivamente, pois não é através de processos de prescrição que tornaremos a formação mais comunicativa. Contudo, entender que os diversos dispositivos tecnológicos nos aproximam e que nessa situação é possível compreendermos e combinarmos aprendizagens contribui de forma significativa para a troca de conhecimentos e torna o ambiente mais comunicativo.

24. FREIRE, Paulo. Extensão ou comunicação. São Paulo: Paz e Terra, 2015. de comunicação", de tal modo que esse acesso à informação seja acompanhado da aprendizagem da crítica, da observação, da criatividade e da expressividade, elementos essenciais nas narrativas dialógicas na contemporaneidade. A dimensão comunicacional é interacionista, já que o ato comunicativo é "a relação que se efetiva pela coparticipação dos sujeitos no ato de conhecer" ${ }^{21}$, pois, como defende Benjaminn², a informação pode inviabilizar as possibilidades de compartilhamento de experiências, uma vez que se esgota em uma conclusão em si, enquanto a narrativa possibilita o diálogo e a partilha de experiências em um processo comunicativo e dialógico.

Ao refletir sobre esse encontro, percebemos na comunicação uma problemática que se alicerça na dificuldade de narrar, de compartilhar experiências e de conectar diálogos, inclusive por parte dos formadores ${ }^{23}$. É importante lembrar que, ao falar de comunicação, não estamos corroborando sua interpretação na perspectiva de transmissão ou de comunicado, ou seja, de informação, mas na acepção vinculada a sua etimologia, advinda do latim communio e communicatio.

Compreendemos que os espaços educativos carecem de práticas comunicativas, o que Paulo Freire ${ }^{24}$ denomina de um ambiente dialógico. Assim, elaboramos diferentes possibilidades de experiências no processo comunicativo, com o uso de diversos suportes tecnológicos e estimulando diferentes linguagens. Tais exercícios evidenciaram certas dificuldades de expressão, ora desencadeadas pela não compreensão da linguagem, ora pela dificuldade de organizar sua expressão de forma distinta da oralidade ou da escrita linear estabelecida na relação professor-aluno.

Diferentes atividades foram propostas em um formato de circuito de experiências: formaram-se grupos de cinco a seis professores, que vivenciavam os espaços para realizar as diferentes experiências. Estas desafiavam os professores a se organizar em atividades corporais e esportivas a partir de diferentes signos para se comunicar, seja por gestos, mensagens de texto em aplicativos, emoticons, linguagem oral ou desenhos.

As vivências oportunizaram a abertura de outras perspectivas para os professores que, ao experimentar novos signos e estratégias para se comunicar, perceberam sutilezas do fazer comunicativo contemporâneo que não faziam sentido para eles até aquele momento. Muitos deles, inclusive, atestaram que passaram a compreender certas expressões que seus alunos usavam e lhes eram indiferentes até aquele momento.

\section{REFLEXÕES SOBRE AS APROXIMAÇÕES DA FORMAÇÃO CONTINUADA: PROCESSOS DE MEDIAÇÃO}

Uma aproximação dos campos da educação e da comunicação numa perspectiva interdisciplinar vem tomando força e visibilidade. Essa tentativa de conjunção se constrói a partir de divergências e convergências referentes à estruturação de um corpus de conhecimento, de metodologias e de objetos de estudo, respeitadas as peculiaridades de cada área do conhecimento, uma vez que ocupam lugares socialmente distintos. 
Nesse sentido, não podemos negar a proximidade desses campos nem uma possível relação entre eles, pois a educação se realiza através da comunicação, assim como o campo da comunicação pode objetivar a educação de tal forma que, para Gutierrez ${ }^{25}$, "quanto mais perfeita seja a comunicação, mais valiosa é, em si, a educação".

Entendemos, com o grupo de professores, nessas e em outras tantas cenas da formação, que o aparecimento de novas formas de narrar o conhecimento nas dinâmicas educacionais não significa uma exclusão das estruturas tradicionais de transmissão de mensagens educacionais, mas uma possibilidade de entendermos o processo educacional como algo complexo e dinâmico, sobretudo quando pensamos nas culturas infantis e juvenis.

A escola, por sua vez, para alunos e professores, pode ser entendida como um dos locais de apropriação de filtros culturais ou, como trata a sociologia latino-americana da comunicação, uma das estruturas de mediação ${ }^{26}$ que podem dar condições de diálogo sobre a cultura midiática. Cremos que não será nas narrativas midiáticas que encontraremos um tratamento crítico sobre as mensagens. Ensaia-se, assim, um novo papel para a escola.

Para além das cenas descritas, os registros nos relatórios da formação apontaram, em síntese, uma percepção de comunicação unidirecional e ainda pouco dialógica dos professores e, portanto, com potência reduzida para pensar os conteúdos da educação física em diálogo com os saberes dos alunos. Apontaram também uma dificuldade de narrar com códigos ou formatos distintos da linguagem escrita ou oral, um indicativo de apropriação ainda em processo das formas de mediação utilizando meios de informação e comunicação.

A partir do contexto explicitado temos nos colocado diferentes possibilidades para pensar a formação continuada no diálogo com a cultura midiática, mas nos parece que alguns elementos devem ser evidenciados, principalmente quando nos questionamos que tipo de formação continuada de professores é ainda necessária para um diálogo com o campo comunicacional. Essa aproximação tem se fortalecido quando as experiências vivenciadas são colocadas como elementos importantes para posterior reflexão, incorporando, assim, os conceitos trabalhados. Em outras palavras: a formação continuada de professores, a nosso ver, não deve se ancorar apenas no discurso da relevância do tema mídia e tecnologia na escola, tampouco na instrumentalização em usos de dispositivos específicos. Antes é necessária uma experiência com o dispositivo em ação para gerar estranhamentos nos imigrantes digitais, como um movimento necessário para o esclarecimento.

Nesse sentido, quando estabelecemos uma perspectiva unilateral de comunicação, foi possível identificar resistências diretas e indiretas por parte dos professores sobre esse diálogo. De forma contrária, ao utilizar uma perspectiva que levava em consideração a experiência narrada pelo professor, com base em sua realidade concreta, pudemos mobilizar sua atenção para o tema.

Identificamos que a narrativa, a comunicação e o processo de mediação são conceitos importantes para os processos formativos de professores e, quando

25. GUTIÉRREZ, op. cit., p. 36.

26. MARTÍN-BARBERO, Jesús. Dos meios às mediações: comunicação, cultura e hegemonia. Rio de Janeiro: Editora UFRJ, 2001. 
materializados em experiências, é possível incorporá-los e ressignificá-los nos diferentes contextos educativos, demonstrando as potencialidades de se acionar a cultura midiática para pensar as práticas pedagógicas da educação física escolar. Igualmente, pensamos que as cenas vividas e relatadas com os professores fazem parte daquilo que Passarelli, Junqueira e Angeluci, chamam de "literais emergentes" que, não estanques no tempo-espaço escolar, estão em contínuo desenvolvimento no que se refere à "a capacidade de se comunicar e interagir utilizando TIC" ${ }^{27}$. Assim, muitas outras cenas virão, com esses e outros professores, bem como com os formadores - todos aprendizes da técnica e da linguagem.

\section{REFERÊNCIAS BIBLIOGRÁFICAS}

BARBIER, René. A pesquisa-ação. Brasília, DF: Líber Livro, 2007.

BELLONI, Maria Luiza. O que é mídia-educação? Campinas: Autores Associados, 2001.

BENJAMIN, Walter. O narrador: considerações sobre a obra de Nikolai Leskov. In: BENJAMIN, Walter. Magia e técnica, arte e política: ensaios sobre literatura e história da cultura. São Paulo: Brasiliense, 1987. p. 197-221.

BIANCHI, Paula. Formação em mídia-educação (física): ações colaborativas na rede municipal de Florianópolis/Santa Catarina. 2009. Dissertação (Mestrado em Educação Física) - Universidade Federal de Santa Catarina, Florianópolis, 2009.

FATIN, Monica. Mídia-educação: conceitos, experiências, diálogos BrasilItália. Florianópolis: Cidade Futura, 2006.

FREIRE, Paulo. Extensão ou comunicação. São Paulo: Paz e Terra, 2015.

GIL, Antonio Carlos. Como elaborar projetos de pesquisa. São Paulo: Atlas, 2010.

GUTIÉRREZ, Francisco. Linguagem total: uma pedagogia dos meios de comunicação. São Paulo: Summus, 1978.

LÉVY, Pierre. A inteligência coletiva: por uma antropologia do ciberespaço. Lisboa: Instituto Piaget, 1994.

MARTÍN-BARBERO, Jesús. Dos meios às mediações: comunicação, cultura e hegemonia. Rio de Janeiro: Editora UFRJ, 2001.

MARTÍN-BARBERO, Jesús. A comunicação na educação. Tradução de Maria Immacolata Vassallo de Lopes e Dafne Melo. São Paulo: Contexto, 2014.

27. PASSARELLI; JUNQUEIRA; ANGELUCI op. cit., p. 163.
MELO, José Pereira; BORBA, Sandra (org.). Caderno informativo do Paideia: a importância do ensino de Arte e Educação Física na escola. Natal: Paideia, 2006. 
MENDES, Diego de Sousa. Luz, câmera e pesquisa-ação: uma inserção na mídia-educação na educação continuada de professores de educação física. 2008. Dissertação (Mestrado em Educação Física) - Universidade Federal de Santa Catarina, Florianópolis, 2008.

PASSARELLI, Brasilina; JUNQUEIRA, Antonio Helio; ANGELUCI, Alan César Belo. Digital natives in Brazil and their behavior in front of the screens. MATRIZes, São Paulo, v. 8, n. 1, p. 159-178, 2014.

PIRES, Giovani De Lorenzi et al. A pesquisa em Educação Física e mídia: pioneirismo, contribuições e críticas ao "Grupo de Santa Maria". Movimento, Porto Alegre, v. 14, n. 3, p. 33-52, 2008.

PORTO, Tania Maria Esperon. As tecnologias de comunicação e informação na escola: relações possíveis... relações construídas. Revista Brasileira de Educação, Rio de Janeiro, v. 11, n. 31, p. 43-57, 2006.

SOARES, Ismar de Oliveira. Gestão comunicativa e educação: caminhos da educomunicação. Comunicação \& Educação, São Paulo, n. 23, p. 16-25, 30, 2002.

SOARES, Ismar de Oliveira. Educomunicação: o conceito, o profissional, a aplicação: contribuições para a reforma do Ensino Médio. São Paulo: Paulinas, 2011.

SOUZA JÚNIOR, Antonio Fernandes de. Os docentes de educação física na apropriação da cultura digital: encontros com a formação continuada. Dissertação. 2018. Dissertação (Mestrado em Educação Física) - Centro de Ciências da Saúde, Universidade Federal do Rio Grande do Norte, Natal, 2018.

WINKIN, Yves. A nova comunicação: da teoria ao trabalho de campo. Campinas: Papirus, 1998. 